\title{
Distribution of CO Concentration in Two Tunnel Models Using CFD
}

\author{
Yong-Ho Lee* \\ (Received September 10, 2012; Revised November 19, 2012; Accepted November 26, 2012)
}

\begin{abstract}
Carbon monoxide (CO) is a primary air pollutant as an indicator of air quality released from motor vehicle combustion. A comparative study of the distributions of $\mathrm{CO}$ concentration with no heat source in two tunnel models open and closed at both end sides is simulated with a commercial CFD code. The tunnel models are used to investigate the $\mathrm{CO}$ concentration distributions at three Reynolds numbers, which are computed by the inlet velocities of $0.3,0.6$ and $1.0 \mathrm{~m} / \mathrm{s}$. For a better tunnel design, the CFD predictive approaches are available in qualitatively studying the distributions of $\mathrm{CO}$ concentration. In the case of the tunnel open at both end sides in sixty seconds, the total $\mathrm{CO}$ concentrations are approximately twenty eight percent higher than those in the closed case.
\end{abstract}

Key words : Carbon monoxide(CO), Tunnel model, CFD (Computational Fluid Dynamics), Reynolds number

\section{Introduction}

Incomplete combustion of hydrocarbon fuels and tobacco smoking are two significant sources of carbon monoxide, which unlike carbon dioxide is highly toxic. Carbon monoxide levels near $15 \mathrm{ppm}$ are harmful and can significantly affect body chemistry. The reaction of humans to different $\mathrm{CO}$ levels varies significantly, and the effects can be cumulative [1]. CO is not only a potentially lethal air pollutant in itself, but also a precursor for other pollutants. Three-dimensional $\mathrm{CO}$ concentration distribution in a two-way underground tunnel was discussed using CFD to validate the model and the concepts used in finding the distribution of $\mathrm{CO}$ concentration measured experimentally [2]. $\mathrm{CO}$ is chosen as an indicator of air quality to assist the design of tunnel ventilation systems. Additionally, air pollutant concentrations of $\mathrm{CO}$ and particle matter less than 1.0 or $2.5 \mu \mathrm{m}$ in diameter have been considered [2,3].

In a general ventilation and transportation system, tunnels are used all the times. According to the increasing number of tunnel structures, a special interest in safety regarding polluted air has significantly grown. Focused on smoke control for fire safety in those various tunnels, many investigations have been carried out. There are three types of tunnels, which are closed at both end sides like a long corridor, closed at one end side like a coal mine tunnel, and open at both end sides like a general road tunnel. In case of a coal mine, one tunnel end is closed, whereas the other is open. The influence of ventilation tube rupture in a coal mine tunnel was investigated by Li kun et al. [4]. The air flow in vertical or horizontal duct systems, in road or railroad tunnels, in highway tunnels, in subway tunnels, etc. is related to the pollutant concentration due to the exhaust gas from

\footnotetext{
† Corresponding Author (Dept. of Automobiles, Chosun College of Science \& Technology, E-mail: toleeyongho@hotmail.com, Tel: 062-230-8330)
} 
vehicles or other accidents.

Vauquelin [5] had experimental investigations carried out on a small scale tunnel model to study the fire-induced smoke control by longitudinal and transverse ventilation systems. The critical air velocity in tunnels for designing and optimizing ventilation and smoke extraction systems was studied by Hwang et al. [6,7] and $\mathrm{Wu} \&$ Baker [8]. The general flow pattern and the back-layering in velocity measured experimentally in the station at different locations were shown to be well matched by the CFD simulations [9].

Yakhot et al. [10] showed that a basic characteristic of the RNG $\mathrm{k}-\varepsilon$ turbulence model involves an analytically derived differential formula for effective viscosity that accounts for lowReynolds number effects. Gebremedhin and $\mathrm{Wu}$ [4] stated that the RNG k- $\varepsilon$ model was found to be the most appropriate model to characterize the flow field in a ventilated space. Nguyen and Reiter [11] evaluated the effects of a building parameter, namely ceiling configuration on wind induced air motion inside a building by using the RNG k- $\varepsilon$ model. Barbason and Reiter [12] reported that certain characteristics of wind flow, such as the creation of regions with very low velocities particularly in near-wall regions, could not be predicted by standard $\mathrm{k}-\varepsilon$ model.

The nature of polluted air flow in a tunnel models was presented by a comparative study using the PIV data acquisition and the CFD analysis [13]. Velocity vector fields, pressure distributions, turbulence kinetic energy as air flow characteristics are discussed in a tunnel model open and closed at both end sides using CFD [14]. Velocity maps, vorticity maps, and kinetic energy distributions based on the reliable field measurement technique and lots of special implementations in the similar tunnel models are investigated by the PIV system $[13,15]$.
The goal of this study is to provide reliable predictions of contaminant distribution in two tunnel models using the ANSYS CFX as a commercial CFD code. The $\mathrm{CO}$ gas flow with no heat source entrained into the model through the inlet is considered in two types of models at three Reynolds numbers. The $\mathrm{CO}$ concentrations and air flow characteristics in connection with flow velocity and pressure distributions in the models are useful in order to provide some desirable information in determining the better ventilation system. This study is particularly focused on the distributions of the $\mathrm{CO}$ concentrations in the models.

\section{Physical Model}

CFD is used to numerically obtain pollutant concentration distributions in two types of the tunnel models. The tunnel models based on a duct ventilation system or a road tunnel are shown in Figure 1. The tunnel model is $800 \mathrm{~mm}$ long and the dimension of the square cross section is $80 \mathrm{~mm}$ $\times 80 \mathrm{~mm}$. The inlet is located at the middle of the tunnel floor in the $\mathrm{x}-\mathrm{z}$ plane, while the outlet is located on the ceiling of the tunnel model at $\mathrm{L}=$ $+60 \mathrm{~mm}$, where $\mathrm{L}$ is defined as a distance from the vertical centerline of the inlet in the $\mathrm{x}$-direction. Each dimension of the inlet and outlet as a rectangular cross-sectional area in the $\mathrm{x}-\mathrm{z}$ plane is $30 \mathrm{~mm} \times 80 \mathrm{~mm}$ both.

Figure 1 shows the computational grids of two types of the tunnel models open or closed at both end sides. The $\mathrm{CO}$ gas flow entering the tunnel model from the inlet is assumed to be steady, and the walls inside the tunnel models are supposed to be adiabatic. The kinematic viscosity of the $\mathrm{CO}$ gas entering the model through the inlet is $13.28 \times 10^{-6} \mathrm{~m}^{2} / \mathrm{s}$, whereas that of the ambient air in the tunnel model is $1.51 \times 10^{-5} \mathrm{~m}^{2} / \mathrm{s}$. The inlet flow velocities are given at $0.3,0.6$, and $1.0 \mathrm{~m} / \mathrm{s}$ in order to analyze the computational $\mathrm{CO}$ 
concentrations in terms of the three different Reynolds numbers.

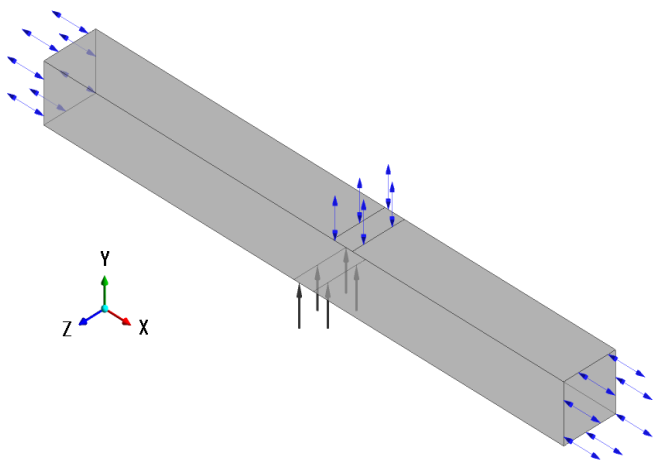

(a) tunnel open at both end sides

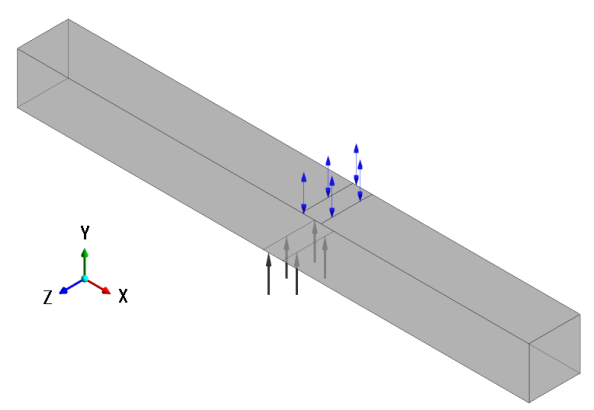

(b) tunnel closed at both end sides

Figure 1: Computational grids of two types of tunnel models at $\mathrm{L}=60 \mathrm{~mm}$

In this paper, heat transfer due to temperature differences in the tunnel models is neglected. Changes in fluid density in the models with no heat source are very small and then the flow inside the tunnel is unsteady and incompressible. Continuity, momentum, concentration analyses except for the energy equation, therefore, are required to be solved simultaneously for five unknowns: pressure, concentration, and three velocities. The effects of changing the $\mathrm{CO}$ concentrations are expressed in time interval of ten seconds in the two different tunnel models.
ANSYS CFX, which is a commercial CFD program, has been implemented. To investigate the effective viscosity at low Reynolds numbers, the Re-Normalization Group (RNG) k- $\varepsilon$ model [10] is used for predicting indoor concentration distributions effectively in two different tunnel models. The transport equation for turbulence dissipation on the RNG $\mathrm{k}-\varepsilon$ model becomes:

$$
\begin{aligned}
& \frac{\partial(\rho \epsilon)}{\partial t}+\frac{\partial}{\partial x_{j}}\left(\rho U_{j} \epsilon\right)=\frac{\partial}{\partial x_{j}}\left[\left(\mu+\frac{\mu_{t}}{\sigma_{\epsilon R N G}}\right)\right]+ \\
& \frac{\epsilon}{k}\left(C_{\epsilon 1 R N G} P_{k}+C_{\epsilon 2 R N G} \rho \epsilon+C_{\epsilon 1 R N G} P_{\epsilon b}\right),
\end{aligned}
$$

where $C_{\epsilon 1 R N G}=1.42-f_{n}$ and $f_{\eta}=\frac{\eta\left(1-\frac{\eta}{4.38}\right)}{\left(1+\beta_{R N G} \eta^{3}\right)}$ etc. The model constants differ from the standard k-emodel, and the constant $C_{\epsilon 1}$ is replaced by the function $C_{\epsilon 1 R N G}$, in which the symbols with meanings and the values of physical constants are given in [16].

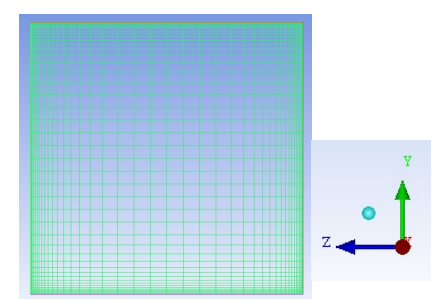

Figure 2: Computational mesh near the walls

ANSYS ICEM CFD is used here as the grid generation tool to create computational mesh from the geometry in Figure 2. To provide a good quality mesh, about 300,000 quadrilateral grids are meshed. The grids are concentrated in the region near the tunnel walls to properly resolve the viscous-affected region. By using an excessively fine mesh near the walls, the validity of near-wall modeling is extended. To satisfy the boundary conditions better, no-slip conditions are imposed on all sides of the walls inside the models. Good 
overall performance in occurring near separation points of the flow in the near-wall region is presented by the grid generation tool.

\section{Results and Discussion}

Two different tunnel models are used to investigate the $\mathrm{CO}$ concentrations in terms of three different Reynolds numbers. The three Reynolds numbers, $V D_{h} / \nu$, of 990,1970 and 3290 are attributed to the flow behavior of $\mathrm{CO}$ gas entrained into the model through the inlet on the bottom floor of the tunnel model. The hydraulic diameter, $D_{h}$, is defined as $4 A / P$, where $A$, the cross-sectional area of the inlet $(30 \mathrm{~mm} \times 80 \mathrm{~mm})$ and $P$, the cross-sectional perimeter of the inlet are calculated here. The longitudinal distance in the horizontal direction from the inlet to the outlet is $+60 \mathrm{~mm}$. The comparison of $\mathrm{CO}$ concentrations with time between the two cases are discussed here according to the three different Reynolds numbers.

\subsection{CO Concentration with Time.}

\subsubsection{Tunnel Open at the Both End Sides}

Caron monoxide concentrations in this paper are expressed as the volume fraction defined as the volume of $\mathrm{CO}$ gas divided by the volume of the ambient air inside the tunnel model. Figure 3 shows the $\mathrm{CO}$ concentrations in the tunnel model open at both end sides at three different Reynolds numbers. The criterion of distance in the model comes from the inlet centerline at half the tunnel height of $40 \mathrm{~mm}$ from the tunnel floor. The positions of $\mathrm{L}= \pm 400 \mathrm{~mm}$ in Figures 3 and $\mathbf{4}$ are referred to distances from the inlet centerline to the both end points in the tunnel model. In the same way, the positions of $\mathrm{L}= \pm 200 \mathrm{~mm}$ lie halfway between the inlet centerline of $\mathrm{L}=0 \mathrm{~mm}$ and the both end points of $\mathrm{L}= \pm 400 \mathrm{~mm}$. The outlet is positioned at a distance of $\mathrm{L}=+60 \mathrm{~mm}$ on the right from the inlet centerline in the $\mathrm{x}-\mathrm{z}$ plane.
In Figure 3 (a), the variation of $\mathrm{CO}$ concentrations with time largely occurs on the right side of the inlet position of $\mathrm{L}=0 \mathrm{~mm}$. It is at very low Reynolds number that the CO concentration variations happen near the outlet. At distance $\mathrm{L}=+200 \mathrm{~mm}$ of the test model, the CO concentrations gradually increase as time goes on. However, other regions except for $\mathrm{L}=+200 \mathrm{~mm}$ are already almost at a volume fraction of 0.99 , even though it takes less than ten seconds for $\mathrm{CO}$ gas to flow into the tunnel.

As the Reynolds numbers are increased as shown in Figures 3 (b) and (c), on the other hand, those similar variations move to the left side from the inlet position. Figure 3 (b) shows the $\mathrm{CO}$ concentrations with time and over different distances from the inlet centerline. It is considered that the $\mathrm{CO}$ concentration levels are governed by the inlet velocities of the $\mathrm{CO}$ source entrained into the model through the inlet. At a distance of $\mathrm{L}=-200 \mathrm{~mm}$ from the inlet centerline, the concentration levels gradually increase over time, although the variation of $\mathrm{CO}$ concentration is not so much high.

The variation of $\mathrm{CO}$ concentration with time at the Reynolds number of 3290 is depicted in Figure 3 (c). In this case, the $\mathrm{CO}$ concentration level at a distance of $\mathrm{L}=-200 \mathrm{~mm}$ starts at the lower value than others, and consequently the concentration changes are larger than those in the case of $\operatorname{Re}=1970$. Although the tunnel model is open at the both end sides, the $\mathrm{CO}$ concentration levels at $\mathrm{L}=-200 \mathrm{~mm}$ are completely different, compared to other positions in the model.

All but the $\mathrm{CO}$ concentrations at a distance of $\mathrm{L}= \pm 200 \mathrm{~mm}$ at three different Reynolds numbers are very high or especially after twenty seconds nearly 0.99 . This is the reason, in all cases of the tunnel model open at both end sides, that the pressure across the tunnel keeps the atmospheric pressure in all regions, even though there is a very 


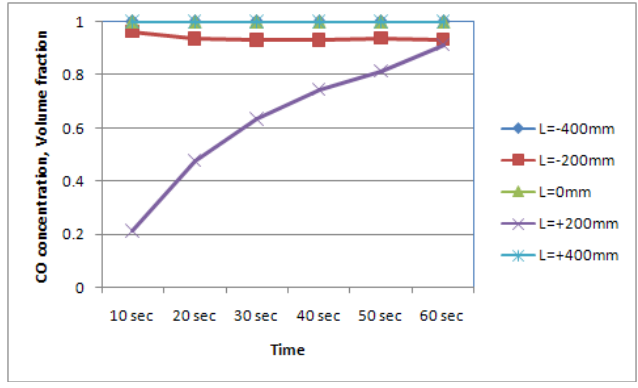

(a) $\mathrm{CO}$ concentrations at $\mathrm{Re}=990$

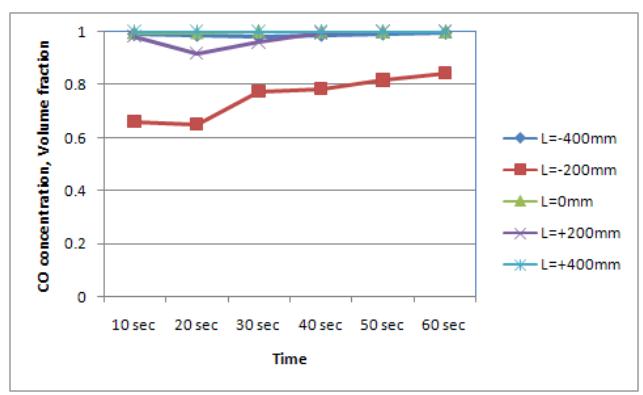

(b) $\mathrm{CO}$ concentrations at $\mathrm{Re}=1970$

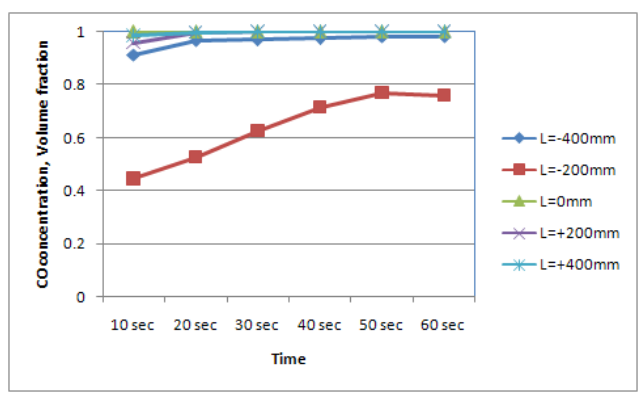

(c) $\mathrm{CO}$ concentrations at $\mathrm{Re}=3290$

Figure 3: $\mathrm{CO}$ concentration levels at given distances from the inlet centerline with time in the tunnel model open at both end sides

little pressure difference near the inlet and outlet regions. In addition, the outlet flow rate at very low Reynolds number is a little high rather than the inlet flow rate. As the Reynolds number increases, however, there is a rapid decrease of each outlet flow rate, compared to the each inlet flow rate [14].

\subsubsection{Tunnel Closed at Both End Sides}

The CO concentration levels in the case of a tunnel model closed at both end sides at the Reynolds number of 990 are shown in Figure 4 (a). For $\mathrm{L}=0 \mathrm{~mm}$ at half the tunnel height of $40 \mathrm{~mm}$ from the floor, the concentration level is nearly 0.99. It implies that the $\mathrm{CO}$ concentrations at $\mathrm{L}=0 \mathrm{~mm}$ have the highest levels regardless of any Reynolds numbers, because the measured points are close to the outlet position of $\mathrm{L}=+60 \mathrm{~mm}$. These trends are almost identical to those in two tunnel models open or closed at both end sides. The

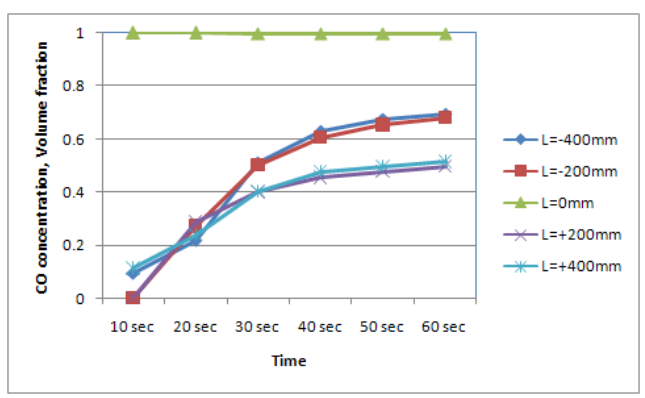

(a) $\mathrm{CO}$ concentrations at $\mathrm{Re}=990$

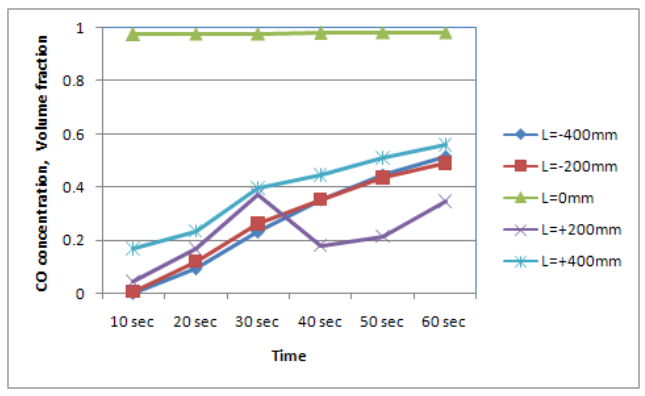

(b) $\mathrm{CO}$ concentrations at $\mathrm{Re}=1970$

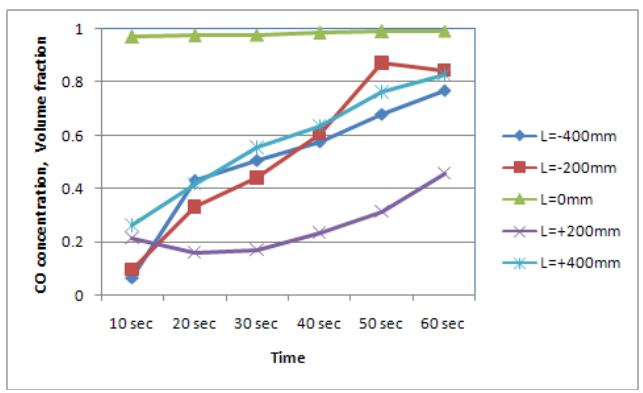

(c) $\mathrm{CO}$ concentrations at $\mathrm{Re}=3290$

Figure 4: $\mathrm{CO}$ concentration levels at given distances from the inlet centerline with time in the tunnel model closed at both end sides 
concentration curves at the two distances of $\mathrm{L}=-200 \mathrm{~mm}$ and $-400 \mathrm{~mm}$, and those of $\mathrm{L}=+200 \mathrm{~mm}$ and $+400 \mathrm{~mm}$ as well, are both coupled and increased over time. In twenty seconds, the $\mathrm{CO}$ concentration levels at $\mathrm{L}=-200 \mathrm{~mm}$ and $-400 \mathrm{~mm}$, where the outlet is farther from the inlet centerline, start to increase higher than those at $\mathrm{L}=+200 \mathrm{~mm}$ and $+400 \mathrm{~mm}$. These flow behaviors happen at a very low Reynolds number only in the tunnel model closed at both end sides.

For the tunnel closed at both end sides at $\mathrm{Re}=1970$ in Figure 4 (b), the CO concentrations excluding the case of $\mathrm{L}=0 \mathrm{~mm}$ are generally lower than those at $\mathrm{Re}=990$. The concentration levels at two distances of $\mathrm{L}=-200 \mathrm{~mm}$ and $-400 \mathrm{~mm}$ identically increase over time. The concentrations, which are a little higher at $\mathrm{L}=+400 \mathrm{~mm}$ than at $\mathrm{L}=-200$ and $-400 \mathrm{~mm}$, increase over time as well, but its levels at $\mathrm{L}=+200 \mathrm{~mm}$ are irregular. The flow behavior near the tunnel outlet at $\mathrm{Re}=1970$ is considered to have a strong effect on the $\mathrm{CO}$ concentration distribution at $\mathrm{L}=+200 \mathrm{~mm}$.

Figure 4 (c) shows the $\mathrm{CO}$ concentration in the tunnel model closed at both sides at $\mathrm{Re}=3290$. It is observed that at $\mathrm{L}=+200 \mathrm{~mm}$, there is a different $\mathrm{CO}$ concentration change decreased first and then increased with the lapse of time. In this case, the outlet flow rate reaches up about 150 percent, when compared to each inlet flow rate, as the Reynolds number increases. For the tunnel closed, the outlet flow rates are higher than the inlet ones with no exception, and the flow behavior appears to be nearly identical[14]. Even so, it is impossible to determine the relationship between the concentration levels and the flow characteristics of flow rates in the outlet or inlet, because the concentration levels in this study are measured at half the tunnel height of $40 \mathrm{~mm}$ from the floor in the $x-z$ plane.

\subsection{Comparison of CO Concentrations in Two Different Tunnel Models}

In order to get deeper information about the concentration difference between the two models in ten seconds after the beginning of the simulation, contour plots of $\mathrm{CO}$ concentrations are shown in Figure 5.
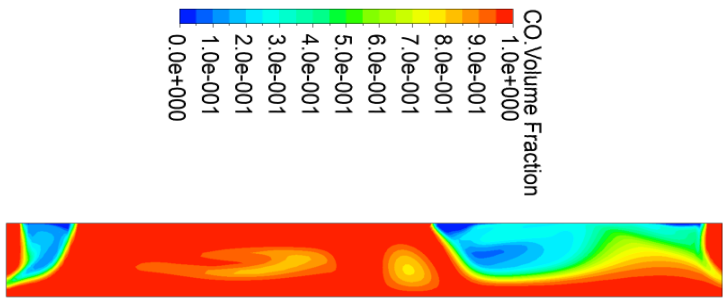

(a) tunnel open at both end sides

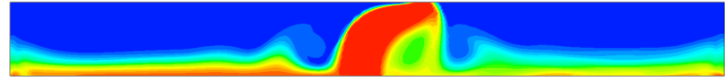

(b) tunnel closed at both end sides

Figure 5-1 CO concentrations at $\mathrm{Re}=990$

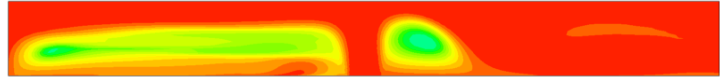

(a) tunnel open at both end sides

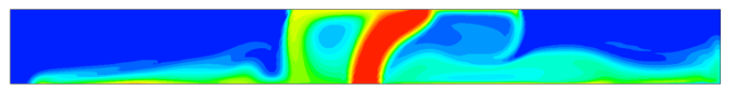

(b) tunnel closed at both end sides

Figure 5-2 $\mathrm{CO}$ concentrations at $\mathrm{Re}=1970$

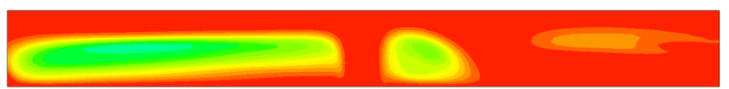

(a) tunnel open at both end sides

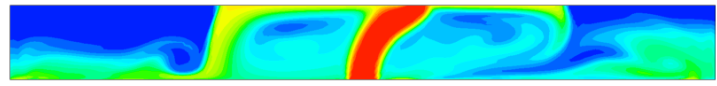

(b) tunnel closed at both end sides

Figure 5-3 $\mathrm{CO}$ concentrations at $\mathrm{Re}=3290$

Figure 5: Contour plots of $\mathrm{CO}$ concentrations at three different Reynolds numbers in ten seconds

Figures 5-1 (a) and (b) show the $\mathrm{CO}$ concentrations at the Reynolds number of 990 regarding two different models open and closed at both end sides. For the model open at both end sides in Figure 5-1 (a), lower concentrations are observed widespread in the right upper region between the outlet and the right end side and, at 
the same time, appear to be limited near the left upper end side. It is considered to affect the whole tunnel due to the $\mathrm{CO}$ concentration change for the short period of time of ten seconds at a very low Reynolds number of 990. In the closed case as shown Figure 5-1 (b), it is observed that most of $\mathrm{CO}$ gas moves toward the outlet and some goes down on the floor. Due to the low inlet velocity in ten seconds and the pressure rise in the model, the distribution of the concentration is chiefly limited between the inlet and outlet regions.

Figures 5-2 (a) and (b) show the contours of $\mathrm{CO}$ concentrations for two different types of tunnel models at the Reynolds number of 1970. In the case of the model open at both end side as shown in Figure 5-2 (a), the $\mathrm{CO}$ concentration levels throughout the tunnel are a bit high. Especially, its levels are higher in the right region from the outlet than those in the left. Just below the outlet in this figure, lower concentration region is formed in circular shape due to the vortex flow. At the same time, a long region of lower concentration is spread out from the left side of the inlet to the left end of tunnel along the central axis. It is considered that as the Reynolds number increases in the tunnel open at both end sides, inlet velocity exerts a stronger influence on the concentrations in a short period of time of ten seconds.

In Figure 5-2 (b), the high concentrations are intensively observed between the inlet and outlet regions. It is assumed that this behavior is caused by the pressure drop, $\Delta P_{\text {closed }}=P_{\text {inlet }}-P_{\text {outlet }}$, which is resulted from the pressure difference between the inlet and outlet in the model closed at both end sides. The CO concentration increases toward both right and left regions from the inlet or outlet, and concurrently toward the bottom floor in the $\mathrm{x}$-direction.

Figures 5-3 (a) and (b) show the concentrations at the Reynolds number of 3290. In the open case as shown in Figure 5-3 (a), the shape of the concentration contour is no big difference from that at the Reynolds number of 1970. The total concentration levels in the left region at $R e=3290$ are a little lower than those at $\mathrm{Re}=1970$. In the closed case as shown in Figure 5-3 (b), the concentration distribution becomes wider and higher in the $\mathrm{x}$-direction due to the increasing inlet velocity of $\mathrm{CO}$ gas.

\section{Conclusions}

In order to gain a better understanding of the $\mathrm{CO}$ concentration distributions, it is desirable to use a CFD analysis, even though good agreement between the CFD simulation and the experimental approach could not be completely reached. Here are two CFD models to predict the CO concentrations expressed as volume fraction. One is the normal tunnel open at both end sides and the other is the tunnel closed like a long corridor. The predicted results using CFD are as follows:

(1) In the tunnel models open or closed at both end sides, most of the $\mathrm{CO}$ concentration levels measured at half the tunnel height of $40 \mathrm{~mm}$ from the inlet position of $\mathrm{L}=0 \mathrm{~mm}$ are nearly 0.99 . It is implied that its inlet flow entering the $\mathrm{CO}$ gas into the model is directly related to the $\mathrm{CO}$ concentration levels in the vicinity of the regions near the inlet and outlet.

(2) At a very low Reynolds number of 990, laminar characteristics in $\mathrm{CO}$ concentration distributions are observed in both cases due to the low inlet velocity. In the open case, the $\mathrm{CO}$ concentration levels are gradually increased near the outlet at $\mathrm{L}=+200 \mathrm{~mm}$. While, in the closed case, four concentration curves except for $\mathrm{L}=0 \mathrm{~mm}$ are grouped into two pairs and then steadily increased over time.

(3) In ten seconds or less, similar trends between the CO concentrations by volume fraction and the 
flow characteristics, such as velocity or pressure distributions, occur in both cases. However, these trends could not be assumed to be continued depending on time.

(4) In the case of the tunnel open at both end sides in sixty seconds, the total $\mathrm{CO}$ concentrations are approximately 28 percent higher than those in the closed case. After sixty seconds, the changing trends in the closed case are assumed to be more apparent than those in the open case because the outlet flow rate is about 50 to 53 percents higher than the inlet one, regardless of changes of Reynolds number [14].

\section{References}

[1] McQuiston and C. Faye, Heating, Ventilating, and Air Conditioning: Analysis and Design, 6/e, John Wiley \& Sons, Inc. 2005.

[2] A. Abbasloo, J. F. Kaljahi, and F. Esmaeilzadeh, "Prediction of three dimesional $\mathrm{CO}$ concentration distribution in zand tunnel of shiraz using computational fluid dynamic method", Journal of Applied Environmental and Biological Sciences, vol. 2, no. 1, pp. 67-76, 2012.

[3] Joel Schwartz and Robert Morris, "Air pollution and hospital admissions for cardiovascular disease in detroit, michigan", American Journal of Epidemiology, vol. 142, no. 1, pp. 23-35.

[4] Li Kun, Ding Cui and You Chang-fu. "Influence of ventilation tube rupture from fires on secondary catastrophes in tunnel". First international symposium on mine safety science and engineering, Procedia Engineering, vol. 26, pp. 75-83, 2011.

[5] Olivier Vauquelin, "Experimental simulations of fire-induced smoke control in tunnels using an 'air-helium reduced scale model' : Principle, limitations, results and future", Tunnelling and
Underground space Technology, vol. 23, pp. 171-178, 2008.

[6] C. C. Hwang and J. C. Edwards, "The critical ventilation velocity in tunnel fires - a computer simulation," Fire Safety Journal, vol. 40, pp. 213-244, 2005.

[7] C. C. Hwang and J. D. Wargo, "Experimental study of thermally generated reverse stratified layers in a fire tunnel." Combust Flame, vol. 66, pp. 171-80, 1986.

[8] Y. Wu and M. Z. A. Baker, "Control of smoke flow in tunnel fires using longitudinal ventilation systems - A study of the critical velocity", Fire Safety Journal, vol. 35 pp. 363-390, 2000.

[9] Y. Nuri, I. B. Muhammed, K. Salih and Nureddin D, "Experimental and numerical simulation of fire in a scaled underground station," World Academy of Science, Engineering and Technology, vol. 40 pp. 309-314, 2008.

[10] V. Yakhot, S. A. Orszag, "Renormalization group analysis of turbulence", Journal of Science Computing, vol. 1, no. 1, pp. 3-51, 1986.

[11] Anh Tuan Nguyen and Sigrid Reiter. "The effect of ceiling configurations on indoor air motion and ventilation flow rates", Journal of Building and Environment, vol. 46, pp. 1211-1222, 2011.

[12] M. Barbason and S. Reiter, "About the choice of turbulence model in building physics simulation", Proceedings of the 7th International Conference on Indoor Air Quality, Ventilation and Energy Conservation in Buildings, Syracuse, New York, 2010.

[13] Y.-H. Lee. "Experimental and CFD simulations of polluted air behavior in rectangular tunnels", Journal of the Korean society of marin engineering, vol. 35, no. 5, pp. 608-615, 
2011.

[14] Y.-H. Lee, "Flow behavior in a rectangular tunnel opened and closed at both sides using CFD". Journal of the Korean Society of Marine Engineering, vol. 36, no. 3, pp. 368-377, 2012.

[15] S.-K. Park, H.-C. Yang, Y.-H. Lee and G. Chen, "PIV measurement of the flow field in rectangular tunnel," Journal of the Korean Society of Marine Engineering, vol. 32, no. 6, pp. 886-892, 2008.

[16] Ansys CFX-solver Theory Guide, Release 13.0, Ansys, Inc., November 2010. 